\title{
Characterization of Myogenic and Vascular Markers in Pompe Patient Samples
}

\author{
Kendra Afonso,* Peter Piepenhagen,* Colleen Lynch,* Susan Ryan* and Beth Thurberg* \\ * Department of Pathology, Genzyme Corporation, One Mountain Road, Framingham, MA 01701
}

Pompe's disease is an autosomal recessive lysosomal storage disorder characterized by a deficiency of acid alpha-glucosidase. Patients lacking this enzyme accumulate glycogen predominately in cardiac and skeletal tissues causing motor, neurological, and respiratory problems in infants. In an attempt to better understand the pathology of the disease and success of current enzyme replacement therapies, eight clinical samples were analyzed for percentage of satellite cells, glycogen, fast versus slow twitch fibers, mannose-6-phophate receptors and (CD31) endothelial markers.

Satellite cells are myofiber precursors located within the sarcolemma and account for less than 5\% of cellular population in normal skeletal tissue. Their self-renewal and repair properties are important for maintenance of damaged muscle. They are normally quiescent and are induced to proliferate and differentiate upon injury. Expression of MRF's (myogenic regulatory factors) MyoD and myogenin is necessary for satellite cell activation. M-cadherin is expressed on quiescent and activated satellite cells and is involved in the fusion of new fibers [1].

The mannose-6-phosphate receptor (CIMPR) is widely expressed and thought to be the primary route of endocytosis and transport of exogenous GAA to lysosomes. Satellite cell markers, fiber typing, and capillary density methods have been utilized to further characterize muscle biopsies in order to better understand variations in patient response.

Comparison of data from satellite cell analysis and glycogen clearance indicates there may be a crude correlation between percentage of activated satellite cells and glycogen clearance. This correlation could reflect two possibilities. First, after treatment with enzyme responders may suffer less muscle damage and hence have less need of satellite cell activation for repair. Another more intriguing possibility is that variations in activated satellite cell density may have some predictive value with regard to patient response.

Given data suggesting that satellite cells may express elevated levels of CIMPR, it is possible they represent a route for GAA internalization through fusion with damaged myofibers. If true, variations in activated satellite cells could explain some of the differences in patient response. Given the nonquantifiable nature of the fiber type data, it was not possible to correlate patient fiber type with glycogen clearance. Quantification of capillary density as an alternative means of assessing fiber type content indicated no obvious correlation with patient response.

\section{Reference}

[1] Sassoon, D. Stem Cells and Cell Signaling, 1st ed. Elseveier, Amsterdam, The Netherlands, 2002. 

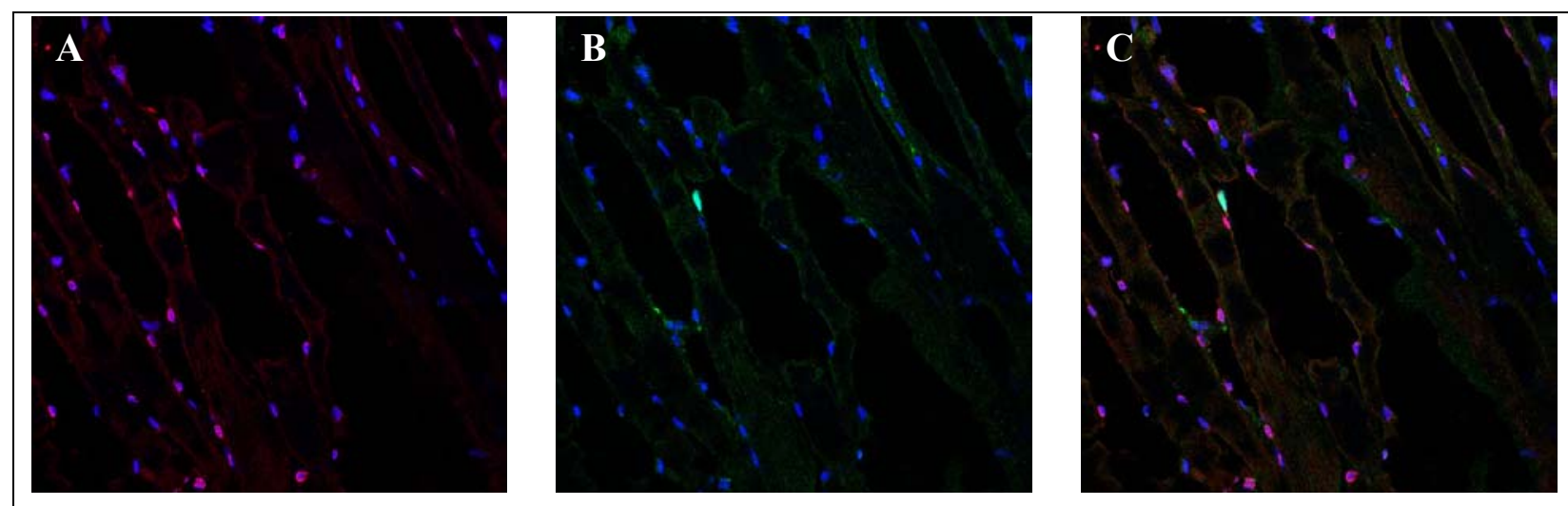

Fig. 1. A. M-cadherin (red) antibody identifies satellite cells in patients affected with pompe's disease. Staining is excluded from nuclei and appears to be cell surface-associated in many cells. B. Myogenin (green) staining is localized to nuclei of activated, differentiating satellite cells. C. Colocalization of m-cadherin (red), myogenin (green), and nuclear (blue) markers in pompe clinical patient. Confirms presence of activated, differentiating satellite cells.

Fig.2. Satellite Cell activation analysis from Pompe patients. Pompe patients were analyzed for total numbers of m-cadherin- and myogenin-positive cells. The ratio of the two provides a measure of satellite cell activity.

TABLE 1.

\begin{tabular}{llllllll}
$\begin{array}{l}\text { Patient } \\
\text { ID }\end{array}$ & $\begin{array}{l}\text { Biopsy } \\
\text { Time } \\
\text { Point }\end{array}$ & $\begin{array}{l}\text { Number } \\
\text { of Fields }\end{array}$ & $\begin{array}{l}\text { Total } \\
\text { Nuclei } \\
\text { (TN) }\end{array}$ & $\begin{array}{l}\text { Total } \\
\text { Satellite } \\
\text { Cell } \\
\text { Nuclei } \\
\text { (SN) }\end{array}$ & $\begin{array}{l}\text { Total } \\
\text { Activated } \\
\text { Cell } \\
\text { Nuclei } \\
(\text { AN) }\end{array}$ & $\begin{array}{l}\text { Satellite } \\
\text { Cells \% } \\
\text { (SN/TN) }\end{array}$ & $\begin{array}{l}\text { Activated Satellite } \\
\text { Cells \% (AN/SN) }\end{array}$ \\
A & $52 \mathrm{wk}$ & 13 & 1457 & 562 & 7 & 39 & \\
C & $52 \mathrm{wk}$ & 14 & 1130 & 469 & 16 & 41.5 & 3.4 \\
D & $52 \mathrm{wk}$ & 14 & 1357 & 426 & 24 & 31.4 & 5.6 \\
E & $52 \mathrm{wk}$ & 14 & 1123 & 396 & 4 & 35.3 & 1.0 \\
F & $52 \mathrm{wk}$ & 14 & 969 & 467 & 10 & 48 & 2.1 \\
H & $52 \mathrm{wk}$ & 14 & 1327 & 458 & 22 & 34.5 & 4.8 \\
\hline
\end{tabular}
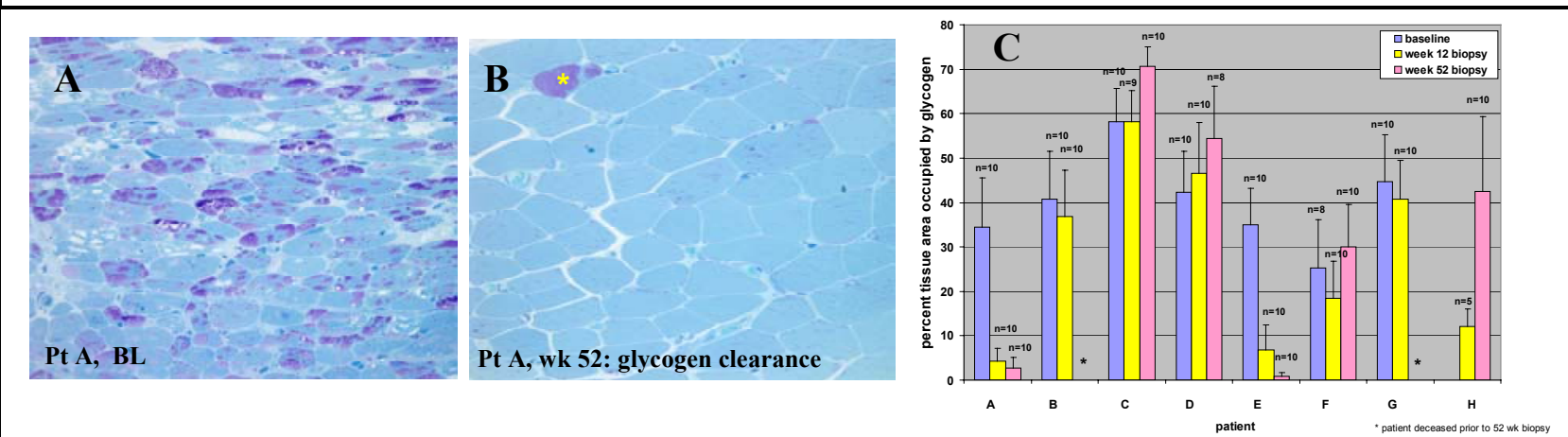

Fig. 3. A. Pompe patient biopsy taken at baseline. The glycogen (pink/purple) has accumulated throughout the fibers in this Pompe patient. B. 52 week biopsy after treatment. There is only one fiber (*) with any significant glycogen accumulation. C. Morphometric analysis of Glycogen clearance in Pompe patients. Values represent percent area of tissue occupied by glycogen \pm standard deviation. Patients A an E respond well to enzyme replacement therapy. 